\title{
Lipopolysaccharide sensitized male and female juvenile brains to ionizing radiation
}

\author{
M Kalm ${ }^{1,4}, K_{\text {Roughton }}^{1,4}$ and K Blomgren ${ }^{\star, 1,2,3}$
}

Radiotherapy is an effective tool in the treatment of pediatric malignancies but it is associated with adverse side effects, both short- and long-term. One common long-term side effect after cranial radiotherapy is cognitive impairment and this is, at least partly, thought to be caused by reduced hippocampal neurogenesis. Neuroinflammation and a perturbed microenvironment are thought to be important in the dysregulation of neurogenesis seen after irradiation (IR). We investigated the effects of a preexisting, lipopolysaccharide (LPS)-induced systemic inflammation at the time of IR in both males and females. A single dose of $8 \mathrm{~Gy}$ to the brain of postnatal day 14 mice caused an upregulation of cytokines/chemokines (IL-1 $\beta$, MIP-1 $\beta$, IL-12, GM-CSF, MIP$1 \alpha$, IL-17, CCL2 and KC) $6 \mathrm{~h}$ after IR, more so in females. Caspase-3 activity, reflecting apoptosis and possibly microglia activation, was elevated $6 \mathrm{~h}$ after IR. Females treated with LPS before IR showed a higher caspase-3 activity compared with males. During the chronic phase (3 months post IR), we found that LPS-induced inflammation at the time of IR aggravated the IR-induced injury in both male and female mice, as judged by reduced bromodeoxyuridine incorporation and neurogenesis (doublecortin-positive cells) in the hippocampus. At this late time point, the microglia density was increased by IR, more so in females, indicating long-term effects on the microenvironment. IR increased anxiety-related behavior in vehicle-, but not LPS-, treated animals. However, exploratory behavior was affected by IR in both vehicle- and LPS-treated mice. In conclusion, we found that LPS administration before IR of the young mouse brain aggravated the injury, as judged by reduced hippocampal neurogenesis. This supports the clinical practice to postpone radiotherapy if the patient shows signs of infection. Systemic inflammation is not always obvious, though, for example because of concurrent corticosteroid treatment, so careful monitoring of inflammation is warranted.

Cell Death and Disease (2013) 4, e962; doi:10.1038/cddis.2013.482; published online 12 December 2013

Subject Category: Neuroscience

Therapy and supportive care are improving and today $80 \%$ of all children who suffer from a brain tumor survive more than 5 years. ${ }^{1}$ Brain tumors represent approximately $30 \%$ of all new hematology/oncology cases in children and adolescents, and the incidence has increased over the last decades. ${ }^{2-4}$ Cranial radiotherapy (CRT), young age at diagnosis and female gender are some risk factors for late-appearing negative side effects, so called late effects. ${ }^{5-8}$ Radiotherapy significantly increases the need for special education in school owing to learning difficulties. ${ }^{9}$ In addition, $50-80 \%$ of the children treated with craniospinal radiation for brain tumors experience growth impairment. ${ }^{10}$ In general, cognitive decline, growth and puberty impairment after radiotherapy are common late effects after CRT. ${ }^{11-16}$

The cause of learning difficulties after irradiation (IR) is believed to partly depend on the injury seen in neurogenic areas, particularly the subgranular zone (SGZ) of the dentate gyrus (DG) in the hippocampus. These areas are highly susceptible to IR-induced injury as demonstrated in both rodents ${ }^{17-22}$ and in humans. ${ }^{23}$ In addition to acute cell loss in the neurogenic areas, IR can influence the survival of stem and progenitor cells in these regions, leading to a limited potential in terms of repopulation or regeneration. ${ }^{17}$ It has been shown in earlier studies that IR to the developing brain induces a transient inflammatory response measured as cytokine and chemokine release ${ }^{24}$ and also activation of microglia. ${ }^{25}$ As long as 1 year after IR, gliosis is still detectable in the DG, indicating a perturbed microenvironment. ${ }^{21}$ It has also been shown in the adult rat brain that IR causes a change in the microenvironment, making the progenitor cells in the DG shift their proliferative response from neurogenesis to gliogenesis, and this was attributed to an inflammatory response. $^{26}$ Inflammatory blockade, using indomethacin, has been shown to protect neurogenesis at least in the adult

\footnotetext{
${ }^{1}$ Center for Brain Repair and Rehabilitation, Institute of Neuroscience and Physiology, University of Gothenburg, box 432, Gothenburg SE 405 30, Sweden; ${ }^{2}$ Department of Pediatrics, University of Gothenburg, Queen Silvia Children's Hospital, Gothenburg SE 416 85, Sweden and ${ }^{3}$ Department of Women's and Children's Health, Karolinska Institutet, Karolinska University Hospital, Q2:07, Stockholm SE 171 76, Sweden

*Corresponding author: K Blomgren, Department of Women's and Children's Health, Karolinska Institutet, Karolinska University Hospital, Q2:07, Stockholm SE 171 76, Sweden. Tel: +46 8517771 83; Fax: 468517 771 83; E-mail: klas.blomgren@ki.se

${ }^{4}$ These authors contributed equally to this work.

Keywords: neurogenesis; radiotherapy; brain tumor; microglia; late effects; cognitive decline

Abbreviations: + , positive; BrdU, bromodeoxyuridine; LPS, lipopolysaccharide; DG, dentate gyrus; GCL, granule cell layer; ML, molecular layer; SGZ, sub granular zone; CRT, cranial radiotherapy; Gy, Gray; Iba-1, ionized calcium-binding adaptor molecule 1; IR, irradiation; P, postnatal day; EPM, elevated plus maze; DCX, doublecortin; TBS, Tris-buffered saline

Received 27.9.13; revised 04.11.13; accepted 05.11.13; Edited by A Verkhratsky
} 
rat brain following IR. ${ }^{27}$ Inflammation in the brain can have negative effects on recovery following injury, but some effects appear to be beneficial and essential. ${ }^{28}$ Therefore, understanding the principles of neuroinflammation is crucial to fully understand the mechanisms of IR-induced injury.

Lipopolysaccharide (LPS) is a surface component of Gramnegative bacteria which causes a direct activation of brain innate immunity. ${ }^{29}$ LPS-induced inflammation in the brain has also been shown to cause negative effects on both neurogenesis and cognitive function. ${ }^{27,30,31}$ Therefore, it is important to investigate if IR- and LPS-induced inflammation have an additive, or even synergistic, effect on the negative outcomes caused by radiotherapy. It is important in a clinical situation to know if side effects from radiotherapy can be aggravated when there is an infection present, even a subclinical infection/inflammation, at the time of treatment. In one of our earlier studies we observed that LPS in combination with IR increased the cytokine response acutely and reduced hippocampal neurogenesis more than IR alone, at least in male mice. ${ }^{32}$ In this study, we investigated sex-dependent differences and/or similarities in animals exposed to both LPS and IR. Previous studies from our group have demonstrated differences between the sexes in behavior and hippocampal neurogenesis in response to IR, where females were more susceptible to IR-induced injuries compared with males. ${ }^{22}$ This holds true for humans as well, where girls have been shown to suffer from adverse late effects to a higher extent than boys. ${ }^{5,33}$ In the current study, we wanted to characterize sex-dependent effects in response to IR-induced injury in combination with LPS administration, both acutely and long term, on a cellular and functional level.

\section{Results}

Experimental design. An overview of the experimental design is shown in Figure 1.

Caspase activity and inflammation. To investigate cell death following IR, we measured the caspase-3 activity (Figure 2). Males and females pretreated with vehicle were significantly affected by IR $(P<0.001)$. LPS-treated animals displayed higher caspase activity in females compared with males after IR $(P=0.024)$. Caspase activity was increased 10-20 times after IR in both males and females, compared with sham treatment in both vehicle- and LPS-treated animals $(P<0.001)$.

The inflammatory response was measured $6 \mathrm{~h}$ post-IR using a 23-plex Luminex assay (Table 1). The vehicle-treated groups displayed an IR-induced increase in the pro-inflammatory cytokines/chemokines IL-1 $\beta$, CCL4 (MIP-1 $\beta)$, IL-12, GM-CSF, CCL3 (MIP-1 $\alpha)$, IL-17, CCL2 (MCP-1) and KC. The LPS-treated animals showed the same pattern, except that no upregulation was seen in CCL4 (MIP$1 \beta$ ) or IL-17. Unlike the vehicle-treated animals, the LPStreated mice showed an upregulation of the pro-inflammatory cytokines/chemokines CCL11 (eotaxin) and IL-9 and of the anti-inflammatory cytokine IL-10 following IR. Moreover, females showed a higher inflammatory response in both vehicle- and LPS-treated animals compared with males after IR (Table 1).

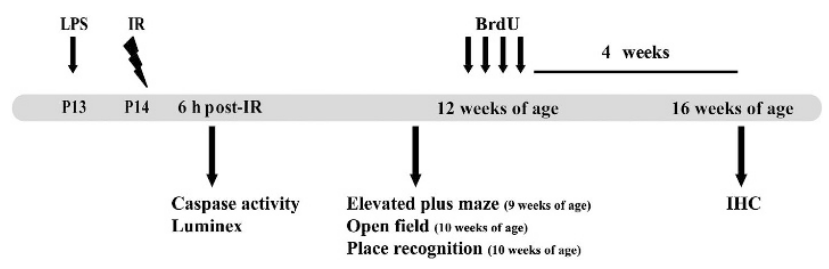

Figure 1 An overview of the timeline of the study. On P13, animals received either an i.p. injection of LPS or vehicle, $24 \mathrm{~h}$ before IR. On P14, the animals were subjected to IR (8 Gy). One group of animals were euthanized $6 \mathrm{~h}$ post IR and used for caspase activity and Luminex assay. The second group was subjected to elevated plus maze, open field and place recognition tests at an age of 10 weeks, subsequently given four consecutive doses of BrdU at the age of 12 weeks and euthanized 4 weeks later (16 weeks of age). The brains collected in the second group were used for immunohistochemistry

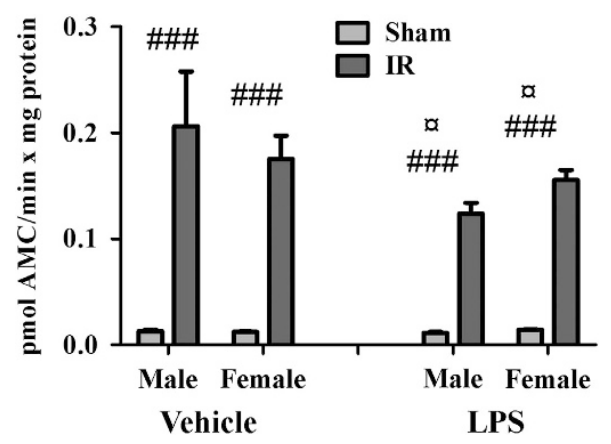

Figure 2 Caspase-3-like activity (DEVDase) $6 \mathrm{~h}$ post IR in brain homogenate (one hemisphere). All data shown as mean \pm S.E.M., $n=6-7$ per group. \# for irradiation, o for sex. ${ }^{\# \# \#} P<0.001,{ }^{a} P<0.05$

Volume and microglia 14 weeks after IR. IR is well known to affect the growth of the DG, as this brain region is still undergoing development at the time of IR. The volume was assessed 14 weeks after IR and there was a clear lack of growth in both vehicle-treated groups (Figures $3 b-e$ ), $P<0.01$, and LPS-treated groups after IR (Figures $3 b-e$ ), $P<0.01$. The total number of microglia in the DG showed a trend toward increased numbers in irradiated females, although not statistically significant (Figure 4b). Owing to the IR-induced lack of growth, the density of microglia in the DG was higher in the vehicle-treated groups after IR (Figure 4b), $P=0.003$. Vehicle-treated males and females both displayed increased microglia density, $16 \%$ and $64 \%$, respectively, compared with non-irradiated brains $(P=0.043)$. In the LPS-treated groups, however, only female brains displayed an increased density of microglia (46\%), whereas male brains displayed a decrease (3\%) after IR (Figure $4 b$ ), $P=0.038$.

Bromodeoxyuridine (BrdU) incorporation and neurogenesis 14 weeks after IR. BrdU incorporation, reflecting proliferation and survival of newborn cells in the entire DG, was quantified 14 weeks post IR. In the vehicle-treated groups, there was a significant interaction between sex and treatment (Figure $5 \mathrm{~b}$ ), $P=0.0016$, where males displayed a $44 \%$ reduction and females a $76 \%$ reduction after IR. Looking specifically at the granule cell layer (GCL) where most of the newborn cells become neurons, the same results 
Table 1 Concentrations of the cytokines and chemokines that were measurable using a 23-plex assay

\begin{tabular}{|c|c|c|c|c|c|c|}
\hline Analyte & Inflammation & Sex & Treatment & Mean & \pm S.E.M. & $\boldsymbol{P}$ \\
\hline \multirow[t]{8}{*}{ IL-1 $\beta$} & \multirow[t]{4}{*}{ Vehicle } & \multirow[t]{2}{*}{ Male } & Sham & 0.078 & 0.003 & \multirow[t]{4}{*}{${ }^{\star}(0.041)$} \\
\hline & & & IR & 0.098 & 0.002 & \\
\hline & & \multirow[t]{2}{*}{ Female } & Sham & 0.096 & 0.002 & \\
\hline & & & & 0.104 & 0.008 & \\
\hline & \multirow[t]{4}{*}{ LPS } & \multirow[t]{2}{*}{ Male } & Sham & 0.080 & 0.000 & \multirow[t]{4}{*}{$* *(0.005)$} \\
\hline & & & IR & 0.088 & 0.002 & \\
\hline & & \multirow[t]{2}{*}{ Female } & Sham & 0.084 & 0.004 & \\
\hline & & & IR & 0.110 & 0.003 & \\
\hline MIP-1 $\beta$ & Vehicle & Male & Sham & 0.020 & 0.000 & \#\#(0.005) . . (0.005) \\
\hline & & & IR & 0.028 & 0.002 & \\
\hline & & Female & Sham & 0.028 & 0.002 & \\
\hline & & & IR & 0.030 & 0.000 & \\
\hline & LPS & Male & Sham & 0.020 & 0.000 & $a(=0.049)$ \\
\hline & & & IR & 0.022 & 0.002 & \\
\hline & & Female & Sham & 0.022 & 0.002 & \\
\hline & & & IR & 0.030 & 0.000 & \\
\hline IL-10 & Vehicle & Male & Sham & 0.010 & 0.000 & NS \\
\hline & & & IR & 0.013 & 0.002 & \\
\hline & & Female & Sham & 0.012 & 0.002 & \\
\hline & & & IR & 0.015 & 0.003 & \\
\hline & LPS & Male & Sham & 0.010 & 0.000 & ${ }^{* *}(0.001)$ \\
\hline & & & IR & 0.010 & 0.000 & \\
\hline & & Female & Sham & 0.010 & 0.000 & \\
\hline & & & IR & 0.018 & 0.002 & \\
\hline IL-12(p40) & Vehicle & Male & Sham & 0.085 & 0.009 & \#\#(0.001) a.a $(<0.001)$ \\
\hline & & & IR & 0.120 & 0.008 & \\
\hline & & Female & Sham & 0.124 & 0.004 & \\
\hline & & & IR & 0.144 & 0.007 & \\
\hline & LPS & Male & Sham & 0.078 & 0.007 & \#\#\#(<0.001) ada $(<0.001)$ \\
\hline & & & IR & 0.106 & 0.006 & \\
\hline & & Female & Sham & 0.106 & 0.002 & \\
\hline & & & IR & 0.138 & 0.004 & \\
\hline IL-12(p70) & Vehicle & Male & Sham & 0.043 & 0.005 & $\#(=0.022)$ a.d $(<0.001)$ \\
\hline & & & IR & 0.062 & 0.004 & \\
\hline & & Female & Sham & 0.068 & 0.004 & \\
\hline & & & IR & 0.074 & 0.007 & \\
\hline & LPS & Male & Sham & 0.042 & 0.004 & $\# \# \#(<0.001)$ a. $(=0.006)$ \\
\hline & & & IR & 0.056 & 0.002 & \\
\hline & & Female & Sham & 0.052 & 0.007 & \\
\hline & & & IR & 0.072 & 0.002 & \\
\hline GM-CSF & Vehicle & Male & Sham & 0.010 & 0.000 & \#(0.024) a. (0.004) \\
\hline & & & IR & 0.020 & 0.003 & \\
\hline & & Female & Sham & 0.022 & 0.002 & \\
\hline & & & IR & 0.024 & 0.002 & \\
\hline & LPS & Male & Sham & 0.010 & 0.003 & $\#(0.049) \cdot 0(0.049)$ \\
\hline & & & IR & 0.016 & 0.002 & \\
\hline & & Female & Sham & 0.016 & 0.002 & \\
\hline & & & IR & 0.020 & 0.000 & \\
\hline CCL3(MIP-1 $1 \alpha)$ & Vehicle & Male & Sham & 0.010 & 0.000 & $\# \# \#(<0.001)$ \\
\hline & & & IR & 0.042 & 0.004 & \\
\hline & & Female & Sham & 0.010 & 0.000 & \\
\hline & & & IR & 0.044 & 0.005 & \\
\hline & LPS & Male & Sham & 0.003 & 0.003 & \#\#\#(<0.001) ad (0.002) \\
\hline & & & IR & 0.026 & 0.004 & \\
\hline & & Female & Sham & 0.010 & 0.000 & \\
\hline & & & IR & 0.040 & 0.003 & \\
\hline CCL11(Eotaxin) & Vehicle & Male & Sham & 0.078 & 0.010 & $a, 0.001)$ \\
\hline & & & IR & 0.110 & 0.012 & \\
\hline & & Female & Sham & 0.132 & 0.008 & \\
\hline & & & IR & 0.142 & 0.012 & \\
\hline & LPS & Male & Sham & 0.068 & 0.009 & \#\#(0.003) .a (0.003) \\
\hline & & & IR & 0.110 & 0.010 & \\
\hline & & Female & Sham & 0.110 & 0.011 & \\
\hline & & & IR & 0.134 & 0.007 & \\
\hline IL-9 & Vehicle & Male & Sham & 0.175 & 0.006 & a.a $(<0.001)$ \\
\hline & & & IR & 0.190 & 0.006 & \\
\hline & & Female & Sham & 0.222 & 0.007 & \\
\hline & & & IR & 0.218 & 0.006 & \\
\hline & LPS & Male & Sham & 0.164 & 0.010 & $\#(0.037)$ a $(0.037)$ \\
\hline & & & IR & 0.180 & 0.006 & \\
\hline & & Female & Sham & 0.180 & 0.017 & \\
\hline & & & IR & 0.214 & 0.007 & \\
\hline
\end{tabular}


Table 1 (Continued)

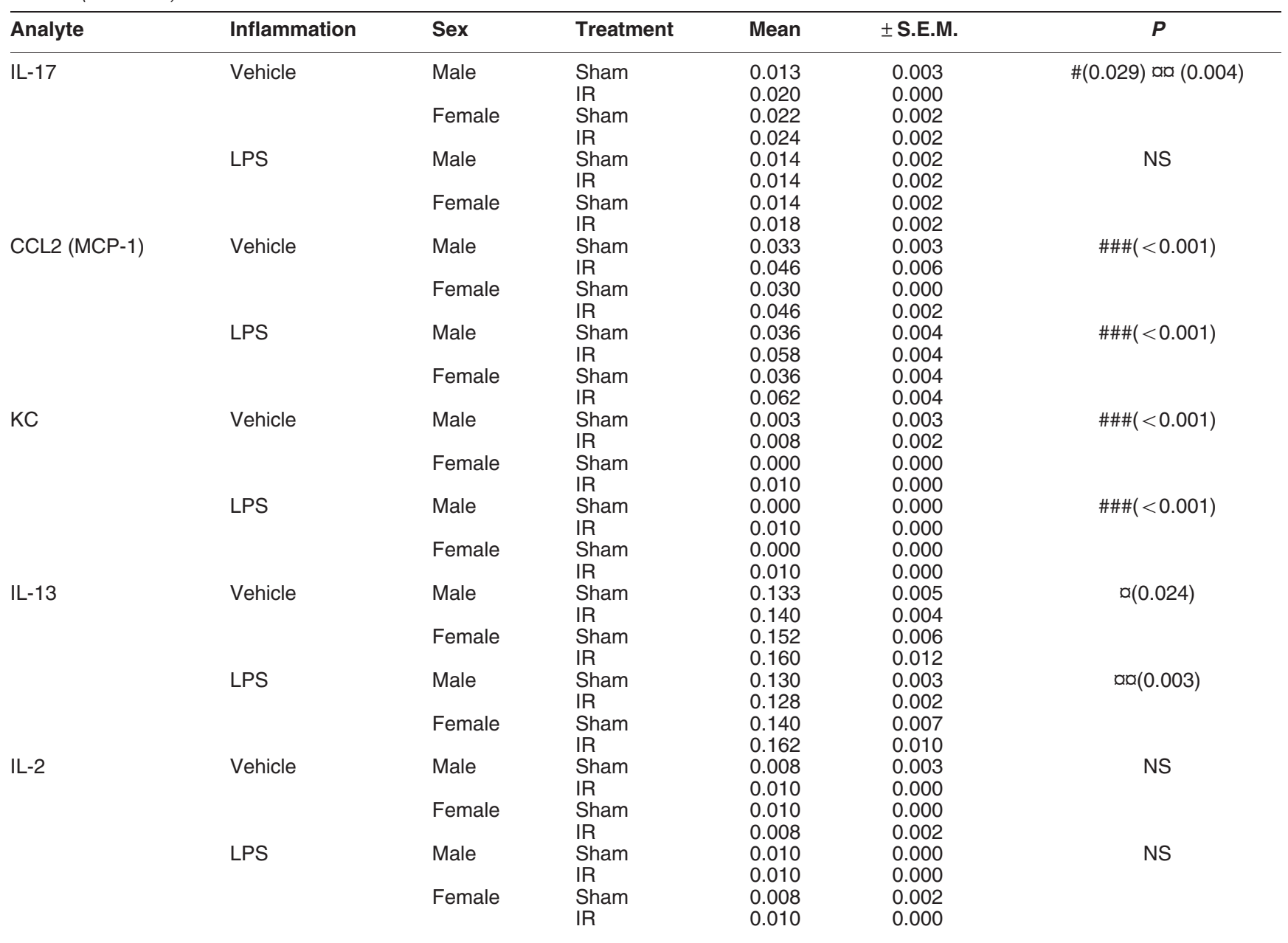

All data shown as mean (pg/mg protein) \pm S.E.M., $n=4-5$ per group. *For interaction between sex and irradiation, ${ }^{\#}$ for irradiation, ${ }^{a}$ for sex. ${ }^{\star} P<0.05,{ }^{* \star} P<0.01$, ${ }^{\#} P<0.05$, "\# $P<0.01$, "\#\# $P<0.001,{ }^{\mathrm{a}} P<0.05,{ }^{\text {ad }} P<0.01$, ${ }^{\text {aro }} P<0.001$

were seen in the vehicle-treated groups following IR (Figure 5c, $P<0.001$ ). In the $\mathrm{GCL}$, the IR-induced reduction was $65 \%$ for males and $87 \%$ for females. In the LPS-treated groups, there was a significant effect of IR in both the DG and the GCL (Figures $5 \mathrm{~b}$ and c, $P>0.001$ ). In the DG, the males had $67 \%$ fewer BrdU-positive cells after IR, and in females the decrease was $69 \%$. In the GCL, the decrease was $86 \%$ for males and $87 \%$ for females.

Comparing only the irradiated groups revealed that inflammation had a significant effect on the outcome following IR. The LPS-treated animals displayed a more pronounced lack of newborn cells compared with vehicle-treated groups in both the DG and the GCL following IR (Figures $5 \mathrm{~d}$ and e, $P=0.019$, and $P<0.001$, respectively). In the DG, the LPStreated males had $21 \%$ fewer BrdU-positive cells compared with vehicle-treated males. For females, this difference was $16 \%$. In the GCL, the difference between the LPS- and vehicle-treated groups was even more pronounced, where males had $44 \%$ fewer BrdU-positive cells and females had $35 \%$ fewer cells when treated with LPS before IR, compared with the vehicle-treated groups.
Neurogenesis 14 weeks after IR, as reflected by the total number of neural progenitor (DCX-positive) cells, was quantified in the $S G Z$ in the DG. Both vehicle- and LPS-treated groups were highly affected by IR, displaying approximately $95 \%$ reduction in DCX numbers in all groups (Figure $6 \mathrm{~b}, P<0.001$ ). Investigating IR alone revealed that the LPS-treated animals were more susceptible to IR compared with vehicle-treated animals in both sexes (Figure 6c, $P<0.001$ ). The LPS-treated male mice had $64 \%$ fewer DCX-positive cells compared with vehicle-treated males. The LPS-treated females had 32\% fewer DCX-positive cells compared with vehicle-treated females following IR.

Behavior: elevated plus maze (EPM), open field and place recognition. Anxiety was assessed using an EPM and an open field arena. Anxiety in the EPM was measured as the time per visit, that is, the less time they spent per visit on the open arm the more anxious the mice were. In the vehicle-treated groups, there was a significant difference in time between sham and irradiated mice, where the irradiated mice spent less time on the open arm (Figure 7a). This 

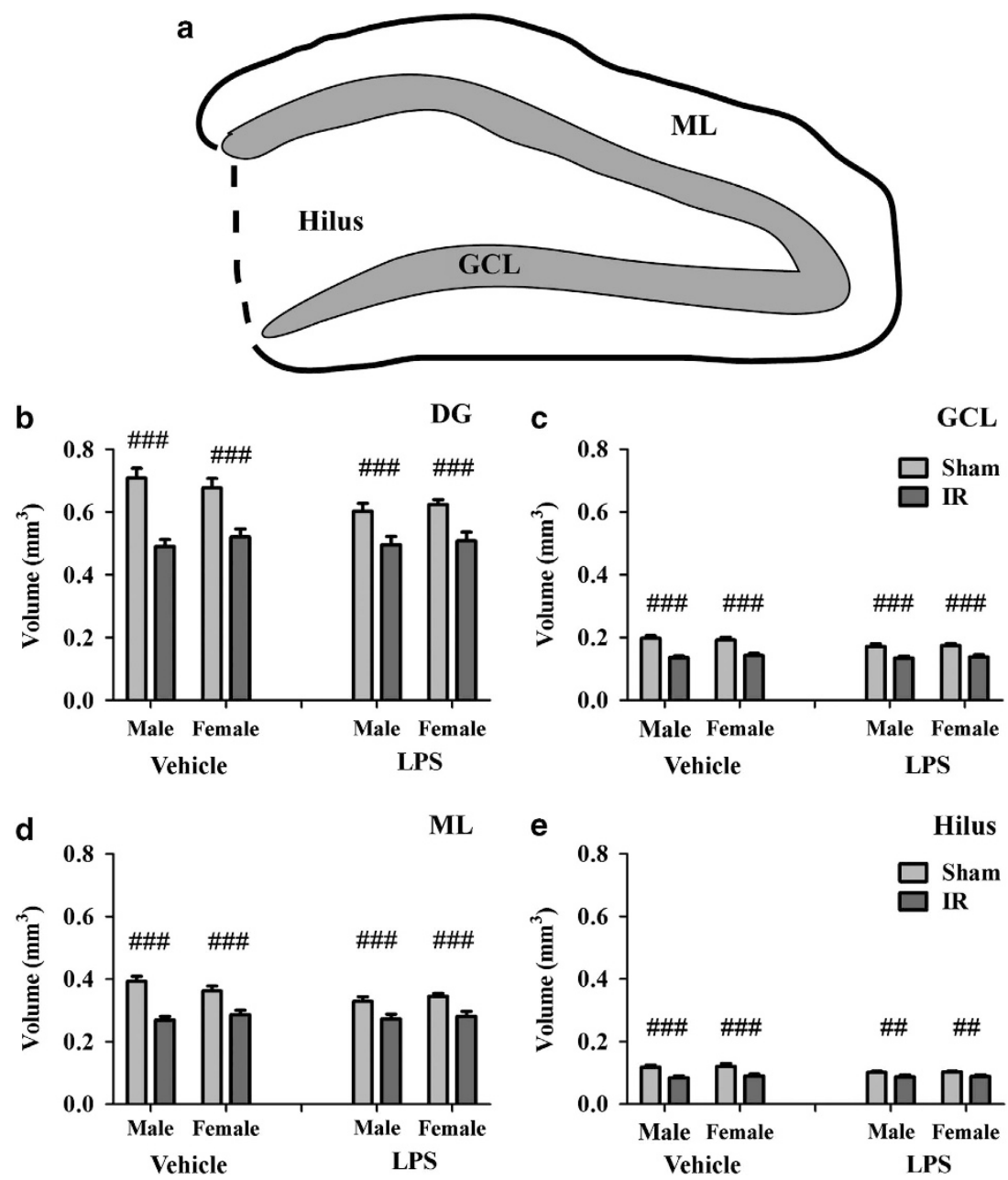

Figure 3 (a) A schematic illustration of the DG including the GCL, the hilus and the ML. (b) The volume of the $\mathrm{DG}$, (c) the GCL, (d) the ML and (e) the hilus in $\mathrm{mm}^{3}$ in vehicle- and LPS-treated animals post IR. All data shown as mean \pm S.E.M., $n=11-14$ per group. ${ }^{\# \#} P<0.01,{ }^{\# \#} P<0.001$

difference was not seen in the LPS-treated groups in either sex. Baseline activity measured as total distance moved in the open field was unaffected by IR in both vehicle- and LPStreated animals (data not shown). However, anxiety in the open field, measured as the average distance from the walls during the experiment, that is, the closer to the wall the mouse stayed the more anxious it was. In the vehicle-treated groups, there was a clear IR effect, where irradiated male and female mice stayed closer to the walls (Figure $7 \mathrm{~b}$ ), $P=0.043$. Again, in the LPS-treated animals no difference between the groups was seen.

To assess exploration and learning after IR, we used a place-recognition test. Exploration was measured as total latency time, that is, the time it took for the mice to approach both objects. During the first testing day, the irradiated groups investigated both object faster compared with sham-treated mice, this was seen in both vehicle- and LPS-treated groups (Figure 7c, $P<0.001$ and $P=0.001$, respectively). During the second day of the experiment, the vehicle-treated male mice took significantly longer to approach the objects compared with the females (data not shown). To assess learning, the discrimination ratio and the percentage of visits to the moved object were measured. The discrimination ratio, that is, total time spent exploring the new object location during the second day compared with the total visit duration, was not different between groups (data not shown). The second learning parameter, percentage of visits to the moved object (i.e., if the value was close to $50 \%$ they approached object one and two to the same extent), did not show any differences between groups (data not shown). The animals visited both objects to the same extent, indicating either that the experimental setup was not optimized properly or that their spatial memory was not affected by IR (data not shown).

\section{Discussion}

This study aimed to investigate if an ongoing inflammation at the time of IR of the whole brain of 14-day-old mice would affect the hippocampus. In a clinical setting, this is comparable to a situation where a patient has a systemic infection, so it is of great importance to know if the negative outcomes from radiotherapy are affected, and if extra caution should be taken. In a previous study, we showed that the combination of LPS and IR decreased hippocampal neurogenesis 2 months 

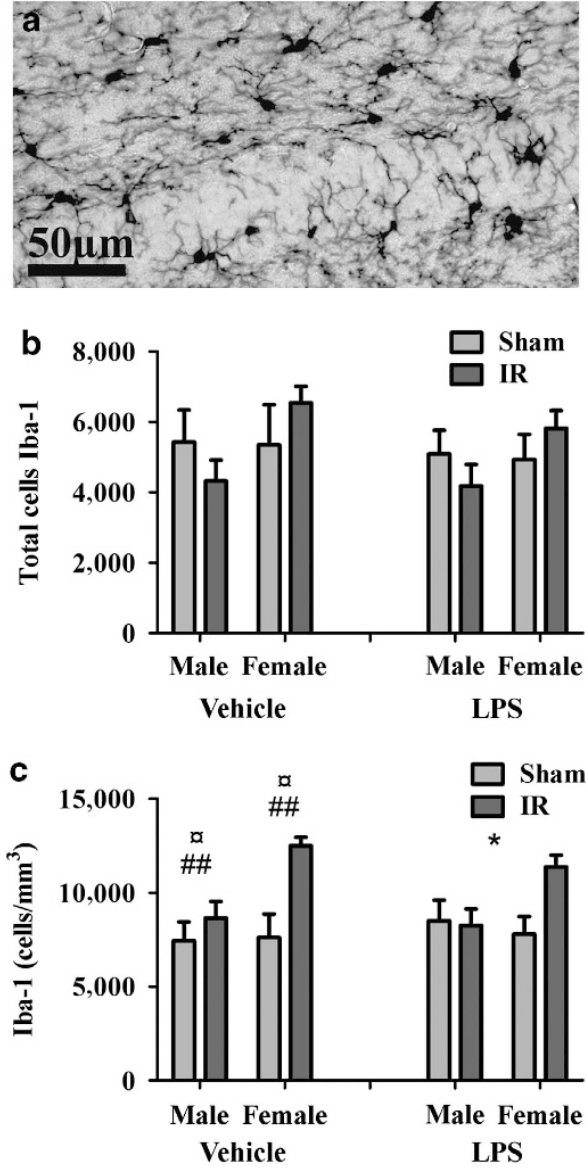

Figure 4 (a) A representative microphotograph of $\mathrm{lba}-1^{+}$cells in the DG from a control animal. Quantification of Iba-1 ${ }^{+}$cells in the DG post IR in vehicle- and LPStreated animals. (b) Total cells and (c) density. All data shown as mean \pm S.E.M., $n=11-14$ per group. * for interaction between sex and irradiation, \# for irradiation, ${ }^{a}$ for sex. ${ }^{*} P<0.05,{ }^{\# \#} P<0.01, P<0.05$ for sex

post IR in male mice. The decrease of neurogenesis was more pronounced when IR was preceded by LPS administration compared with IR alone. ${ }^{32}$ We have also demonstrated that neurogenesis was reduced more and anxiety increased more in female than in male mice after IR. ${ }^{22}$ The current study was extended to investigate the effects of a concurrent inflammation at the time of IR in both males and females.

More pronounced cell death and inflammation during the acute phase. Preconditioning, also known as tolerance (a prior sublethal exposure renders the tissue less sensitive to a subsequent severe insult), induced by LPS treatment has been demonstrated in the developing brain for different injuries, such as hypoxia-ischemia and seizures. ${ }^{34}$ LPS or IR alone, can both cause neuroinflammation. IR to the young brain causes a transient upregulation of cytokines and chemokines (e.g., CCL2 and IL-1 $\beta$ ), activation of microglia (morphology, ionized calcium-binding adaptor molecule 1(lba-1)), oxidative stress (nitrotyrosine) and cell death (TUNEL, p53 and cleaved caspase-3) during the acute phase. ${ }^{20,24,25}$ LPS administration is commonly used to investigate acute neuroinflammation. Similar LPS doses as the one used in the current study have been shown to induce neuroinflammation in the adult brain and cause reactive microgliosis, at least partly through activation of Toll-like receptor 4, contributing to neuronal dysfunction and degeneration through the release of inflammatory and neurotoxic factors (IL-6, TNF- $\alpha$, IL-1 $\beta$, nitric oxide, reactive oxygen species). ${ }^{29,35,36}$ The inflammatory response is also highly upregulated in the immature brain after LPS exposure. ${ }^{37}$ In the current study, we observed that both caspase-dependent cell death and inflammation were increased $6 \mathrm{~h}$ post IR. If a preexisting inflammation was present, females displayed a more pronounced caspase-dependent cell death compared with males. Also in terms of inflammatory mediators $6 \mathrm{~h}$ post $I R$, females showed higher levels of cytokines and chemokines than males in both vehicle- and LPS-treated animals. In summary, unlike the protective preconditioning effect observed when LPS treatment $24 \mathrm{~h}$ later is followed by an ischemic insult, we observed an aggravating, sensitizing effect.

Microgliosis, reduced neurogenesis and cell survival followed LPS and IR. Late-occurring effects of LPS and IR were studied 14 weeks post LPS and IR. It has been shown that months after a single dose of 8 Gy to the young mouse brain, hippocampal neurogenesis is almost abolished, and no recovery was seen over time..$^{21,38}$ The diminished neurogenesis seen after IR has been shown to be more pronounced in female mice. ${ }^{22}$ It is well known that IR to the developing brain causes growth retardation of the $D G,{ }^{20,22,38,39}$ but a dose of $0.3 \mathrm{mg} / \mathrm{kg}$ of LPS aggravates the IR-induced injury, at least in male mice. ${ }^{32}$ In this study, where the volumes were evaluated at a later time point, we could only see IR-dependent lack of growth, indicating that the effect of LPS observed previously disappeared with time.

In the current study, we evaluated the effects on microglia, proliferation, cell survival and neurogenesis 3 months after IR. To investigate microglia, we used lba-1, which is as a general marker for all such cells regardless of activation state. Microglia are constantly surveying the environment in the search of possible threats; during pathological conditions, they become activated and secrete pro-inflammatory molecules. ${ }^{27,40}$ In this study, microglia density was affected by IR in the vehicle-treated groups, more so in females. The same was seen in LPS-treated females. When counting the total number of microglia in the DG, we observed the same trends as for the densities, but they did not reach statistical significance. The IR-induced growth impairment observed in neurogenic regions like the hippocampus, eventually yielding a smaller DG volume, enhanced microglia density, just like astrocyte density was earlier shown to be increased. ${ }^{21}$ Microvessels, on the other hand, adapt to the altered growth, ${ }^{38}$ so this must be investigated for each parameter. It has been proposed that there is a cross talk between microglia and the newly formed neurons and that this is beneficial for neurogenesis. ${ }^{41}$ However, in the injured brain this cross talk is presumably disturbed by sustained activation of microglia. In the young brain, it has been shown that microglia are susceptible to IR and that a portion of them have died 1 week following IR. ${ }^{25}$ This early loss of microglia had recovered 8 weeks post IR. ${ }^{32}$ In the current study, where animals were evaluated 14 weeks post IR, the microglia density was even higher, especially in 

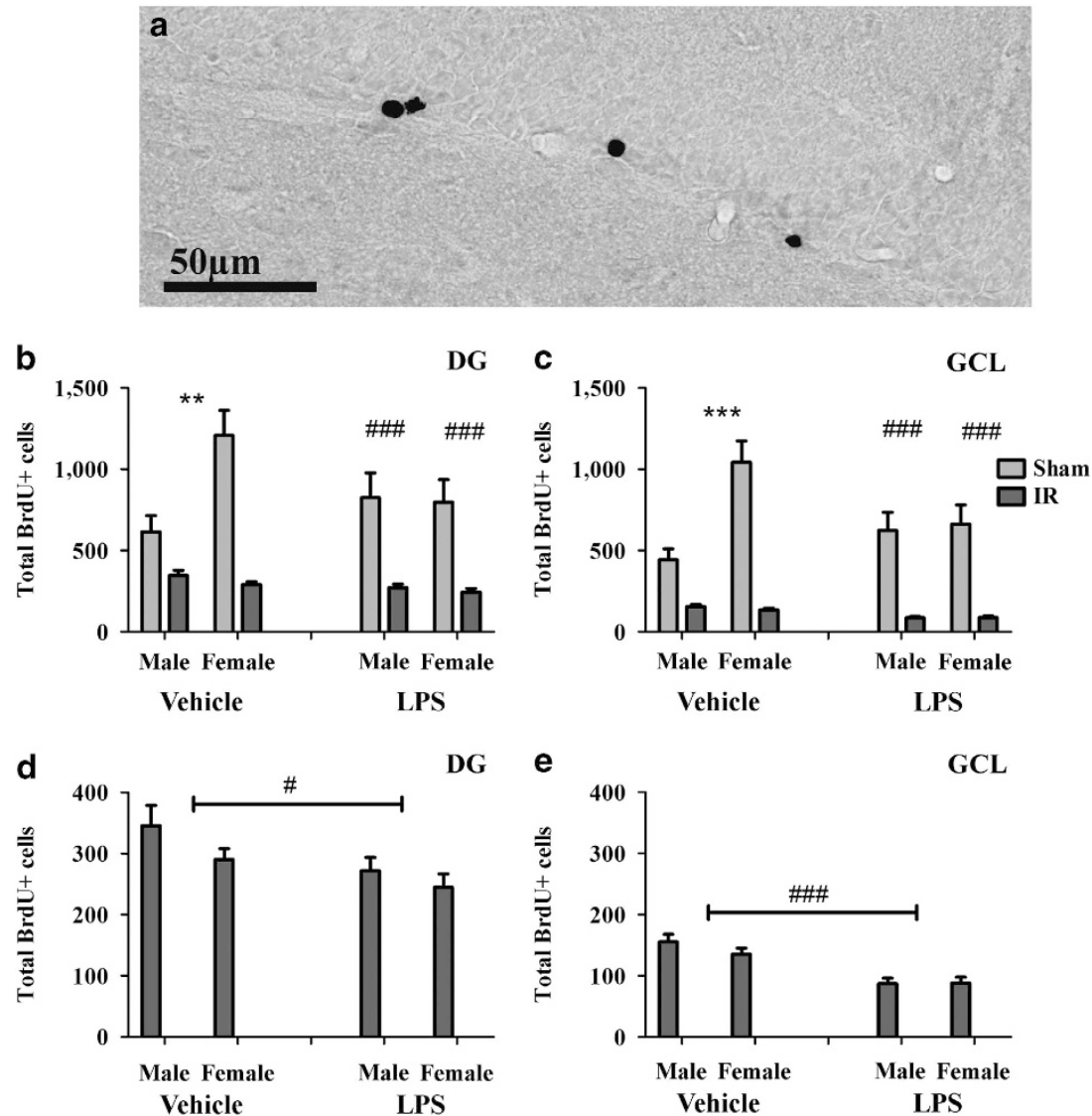

Figure 5 (a) A representative microphotograph of $\mathrm{BrdU}^{+}$cells in the $\mathrm{GCL}$. (b) Quantification of $\mathrm{BrdU}^{+}$cells in the $\mathrm{DG}$ and (c) in the $\mathrm{GCL}$ in vehicle- and LPS-treated animals post IR. (d and e) Quantification of $\mathrm{BrdU}^{+}$cells in the DG and the GCL, respectively, in only vehicle- and LPS-treated animals subjected to IR. All data shown as mean \pm S.E.M., $n=12-14$ per group. ${ }^{*}$ Interaction between sex and irradiation, \# for irradiation. ${ }^{* *} P<0.01,{ }^{* \star *} P<0.001,{ }^{\#} P<0.025$, $\# \#+0.001$
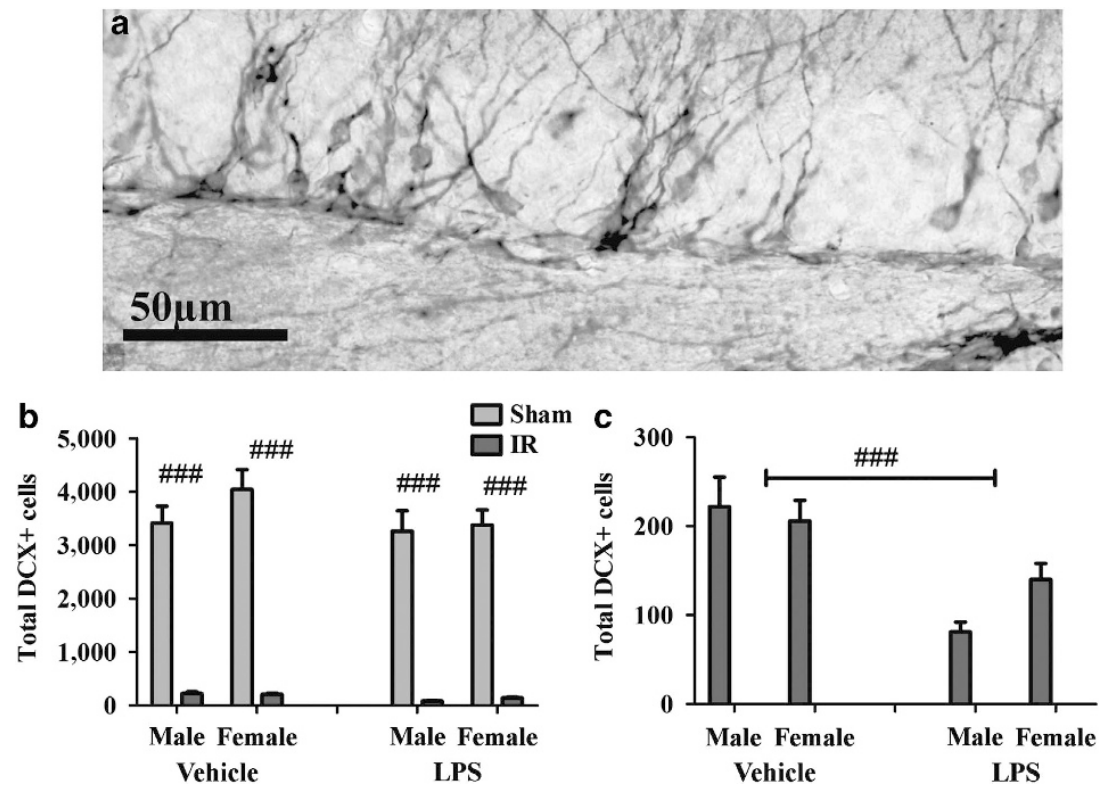

Figure 6 (a) A representative microphotograph of $\mathrm{DCX}^{+}$cells in the GCL. (b) Quantification of $\mathrm{DCX}^{+}$cells in the GCL in vehicle- and LPS-treated animals post IR. (c) Quantification of $\mathrm{DCX}^{+}$cells in the GCL in only vehicle- and LPS-treated animals subjected to IR. All data shown as mean \pm S.E.M., $n=12-15$ per group. \# for irradiation. ${ }^{\# \# \#} P<0.001$ 

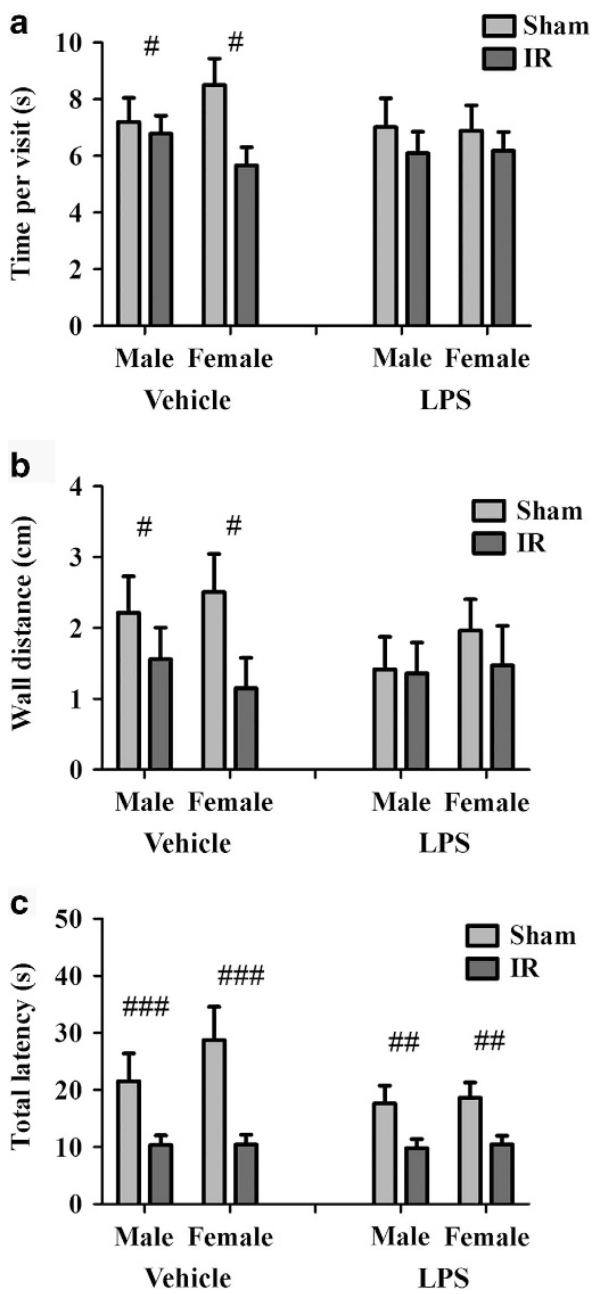

Figure 7 (a) Time per visit in the elevated plus maze and (b) distance to the walls in the open-field arena in vehicle- and LPS-treated animals. (c) The total latency, that is, the time it took for the animals to explore both objects on the first day of the place recognition test in vehicle- and LPS-treated animals. All data shown as mean \pm S.E.M., $n=12-15$ per group. \# for irradiation, ${ }^{\#} P<0.05$, ${ }^{\#} P<0.01$, $\# \# P<0.001$

females, who also sustained a greater IR-induced injury. This demonstrates IR-induced long-term changes to the developing brain tissue, including inhibitory effects on neurogenesis. During the last years, the classification of macrophages as either having a toxic, pro-inflammatory phenotype (M1) or an alternative protective, anti-inflammatory phenotype (M2) has been applied to microglia. ${ }^{42}$ It is tempting to speculate that IR induced predominantly the M1 phenotype of microglia. Whether this is the case and if there is a difference between males and females remains to be elucidated.

To investigate proliferation and cell survival, we looked at BrdU incorporation 10 weeks after IR, evaluated 4 weeks later. In the DG, the irradiated, vehicle-treated females showed a more pronounced loss of proliferation and survival compared with males, as judged by BrdU-incorporation post IR (44\% loss in males and $76 \%$ loss in females). This has also been shown in adult animals subjected to IR. ${ }^{43}$ In the LPStreated animals, differences between the sexes were not observed and both sexes showed a similar loss $(67 \%$ loss in males and $69 \%$ loss in females). The bulk of the cytogenesis in the DG was found in the GCL, where neurogenesis occurs, and the GCL was more radiosensitive than the rest of the $D G$. Newborn neurons, measured as DCX-positive cells, were highly affected by IR in both vehicle-and LPS-treated animals. The effects of IR on newborn cells in this region are of particular interest because of the proposed role of young neurons in the GCL in memory and learning. ${ }^{44}$ In the adult DG, newborn neurons migrate from the SGZ into the GCL, integrate into the existing circuitry and receive functional input. ${ }^{45}$ The survival of newborn cells is regulated through diverse mechanisms and many of them die within 4 weeks after birth. We evaluated BrdU incorporation 4 weeks after the injections, allowing for both normal, developmental death of progenitors, and maturation into a postmitotic, neuronal phenotype. Once they mature, the granule cells receive excitatory glutamatergic input mainly from the entorhinal cortex and GABAergic input from interneurons within the DG. ${ }^{45,46}$ LPS aggravated the IR-induced decrease in cell survival and loss of neurogenesis in both sexes. As discussed above, both LPS and IR alone have negative effects in the acute phase, which could explain why we see an additive effect in reduced cell survival and neurogenesis when combining the two. Interestingly, in Parkinson's disease models, LPS was shown to induce microglia activation causing dopaminergic neurodegeneration both in vivo and in vitro. ${ }^{47}$ This supports our findings that the LPS treatment caused neuroinflammation, which sensitized the brain to the subsequent IR, causing a more pronounced IR-induced injury. 24,25,29

Altered behavior followed LPS and IR. One important late effect of CRT is reduced cognitive capacity, where pediatric brain tumor survivors develop at a slower rate compared with their peers. ${ }^{8}$ Declines in IQ observed after IR are most likely a result of failure to learn at a rate that is appropriate for the age of the child rather than from a loss of previously acquired knowledge. ${ }^{8}$ In addition to reduced attention span, this type of learning deficit indicates an impaired hippocampal memory system. ${ }^{48}$ It is important in preclinical studies to find functional correlates of cognitive deficits in patients. Using IntelliCage, where learning and memory can be assessed in a home-cage setting, we have shown that IR affects the developing brain and that it has negative behavioral effects. ${ }^{49}$ The negative outcomes observed in behavior were more pronounced in females. ${ }^{22}$ We have shown that anxiety levels are influenced by IR to the developing brain, as measured in an open-field arena, where females were more prone to anxious behavior than males. ${ }^{22,49}$ Supporting this, studies in adult mice using contextual fear conditioning, have shown IR-induced deficits only in females. ${ }^{50}$ However, another study failed to see sex- or IR-induced effects in adult animals using the same behavioral test. ${ }^{43}$ Contextual fear conditioning has also been used in male mice exposed to IR at a young age, and consistent with the studies just mentioned, no differences were detectable after IR. ${ }^{49}$ As mentioned in the results, the place recognition task failed to discriminate between the groups, either because it was not optimized properly or because the spatial memory of the mice was not affected by IR. ${ }^{51}$ Nevertheless, we observed an 
IR-induced difference in anxiety and exploratory behavior. Our results from the EPM and the open-field test together showed that vehicle-treated animals subjected to IR were more prone to anxious behavior. Interestingly, this difference disappeared if the animals were pretreated with LPS. The results indicate that LPS alone affected behavior, a finding supported by other studies. ${ }^{30,31,52}$ In a study where prenatal exposure to LPS was investigated, enhanced anxiety using open field and EPM was detected. ${ }^{52}$ They also showed that LPS-treated rats had lower levels of $5-\mathrm{HT}_{1 \mathrm{~A}}$ receptors in the hippocampus, and they speculate that this is one of the major causes of anxiety-like behaviors. ${ }^{52}$ Both the dorsal and the ventral hippocampus had lower levels of $5-\mathrm{HT}_{1 \mathrm{~A}}$ receptors, where the levels in the ventral hippocampus could explain the increased anxiety because of its involvement in emotional behaviors. ${ }^{53}$

Concluding remarks. In conclusion, we found that concurrent inflammation at the time of IR had an additive effect on the IR-induced injury in both male and female mice, as judged by reduced hippocampal cytogenic capacity and neurogenesis. A pre-existing inflammation at the time of IR affected both sexes to the same extent. The cytokine/ chemokine profile induced by IR was different in the brains of mice treated with LPS $24 \mathrm{~h}$ earlier, and different between males and females. The density of microglia was subsequently increased, indicating long-term changes in the microenvironment that may have a negative influence on hippocampal neurogenesis. A systemic inflammation, caused for example by an infection, at the time of radiotherapy may aggravate the negative side effects of CRT in patients. In clinical practice, radiotherapy is usually postponed if patients have a symptomatic infection, but our data indicate that even asymptomatic inflammation may be harmful and cytokine profiling could be a useful tool in this respect. We demonstrate that our model is useful to investigate differences between males and females in terms of IR-induced CNS late effects.

\section{Materials and Methods}

Animals. Male and female C57BL/6J mice were purchased from Charles River Laboratories, Sulzfeld, Germany. The animals were kept on a 12-h light cycle. Food and water were provided ad libitum. Animals were blindly assigned to the different groups. Animals were administered an intraperitoneal injection of lipopolysaccharide (LPS) from Escherichia coli 026:B6 (Sigma-Aldrich, St Louis, $\mathrm{MO}, \mathrm{USA}$ ) dissolved in $0.9 \%$ sodium chloride, $\mathrm{NaCl}$, to a concentration of $0.015 \mathrm{mg} / \mathrm{ml}$ and a dose of $0.3 \mathrm{mg} / \mathrm{kg}$ was administered $24 \mathrm{~h}$ before IR, on postnatal day $13(\mathrm{P} 13)$. Animals assigned to vehicle treatment were given $0.9 \%$ sodium chloride $24 \mathrm{~h}$ before IR, on postnatal day 13 (P13). Animals used for longterm experiments were weaned on P21. All experiments were approved by the Gothenburg committee of the Swedish Animal Welfare Agency (47-2011).

IR procedure. For the IR procedure, we used a linear accelerator (Varian Clinac 600 CD; Radiation Oncology Systems LLC, San Diego, CA, USA) with $4 \mathrm{MV}$ nominal photon energy and a dose rate of $2.3 \mathrm{~Gy} / \mathrm{min}$. Male and female littermates were anesthetized on P14 with an intraperitoneal injection of tribromoethanol $(50 \mathrm{mg} / \mathrm{kg})$ and placed in prone position on a polystyrene bed. The head was covered with a $1-\mathrm{cm}$ tissue-equivalent bolus material to obtain an even IR dose throughout the underlying tissue. The whole brain was irradiated using a field of $2 \times 2 \mathrm{~cm}$ and a source-to-skin distance of approximately $99.5 \mathrm{~cm}$ to yield an absorbed dose of $8 \mathrm{~Gy}$. A single dose of $8 \mathrm{~Gy}$ is equivalent to $18 \mathrm{~Gy}$ delivered in 2 Gy fractions according to the linear quadratic formula and an alpha/ beta ratio of 3 for late effects in the normal brain tissue..$^{54}$ Control animals were anesthetized but not subjected to IR. After IR, the pups were returned to their dams. Animals were euthanized $6 \mathrm{~h}$ post IR (26 males and 27 females) or 14 weeks post IR (16 weeks of age; 60 males and 60 females). For the groups euthanized $6 \mathrm{~h}$ post IR, six or seven animals were assigned per group. For the animals euthanized 14 weeks post IR, three animals from different groups died for unapparent reasons during the experiment $(n=14-15$ per group at the time for euthanization).

Immunoassay (luminex). Animals used for analysis of brain cytokines were euthanized by decapitation $6 \mathrm{~h}$ after IR. The brains were quickly dissected out, frozen in isopentane and dry ice, and stored at $-80^{\circ} \mathrm{C}$. The right hemisphere was homogenized (without the olfactory bulb) by sonication in $1 \mathrm{ml}$ of phosphatebuffered saline containing $0.1 \%$ Triton $\mathrm{X}-100,1 \%$ protease inhibitor cocktail (Complete mini, Roche diagnostics GmbH, Pentberg, Germany) and $5 \mathrm{~mm}$ EDTA. Crude cytosolic fractions were produced by centrifuging homogenates at $15000 \times \mathrm{g}$ for $10 \mathrm{~min}$ at $4{ }^{\circ} \mathrm{C}$ and subsequently stored at $-80^{\circ} \mathrm{C}$. The protein concentrations were determined according to Whitaker and Granum. ${ }^{55}$ Crude cytosolic fractions were assayed for the following mouse cytokines/chemokines: IL-1 $\alpha$, IL-1 $\beta$, IL-2, IL-3, IL-4, IL-5, IL-6, IL-9, IL-10, IL-12p40, IL-12p70, IL-13, IL-17A, eotaxin, G-CSF, GM-CSF, IFN- $\gamma$, KC, CCL2 (MCP-1), CCL3 (MIP-1 $\alpha$ ), MIP- $1 \beta$, RANTES and TNF- $\alpha,(n=4-5$ per group, duplicate samples, randomly assigned from each group to fit the plate) using a multiplex mouse assay (Bio-Plex Pro Mouse Cytokine Standard 23-Plex, Group 1, Lot \#5022433-1, Bio-Rad Laboratories $A B$, Sundbyberg, Sweden), essentially according to the protocol of the manufacturer. Samples were analyzed using the Bio-Plex Protein Array System and the related Bio-Plex Manager (Bio-Rad, Sundbyberg, Sweden).

Caspase activity assay. The sample preparation and protein concentrations were determined as above. Samples of homogenate $(20 \mu \mathrm{l})$ were mixed with $80 \mu \mathrm{l}$ of extraction buffer ( $n=6-7$ per group, duplicate samples) and analyzed as described earlier. ${ }^{56}$ Cleavage of Ac-DEVD-AMC (for caspase-3/7 activity, Peptide Institute, Osaka, Japan) was measured with an excitation wavelength of $380 \mathrm{~nm}$ and an emission wavelength of $460 \mathrm{~nm}$, and expressed as pmol AMC released per $\mathrm{mg}$ protein and minute.

Bromodeoxyuridine labeling. Animals were given one daily injection of bromodeoxyuridine (BrdU; $50 \mathrm{mg} / \mathrm{kg}$ ), a marker of the total cytogenic capacity, for four consecutive days 10 weeks after IR, when the behavior testing was finished to avoid possible influence on cytogenesiss outcomes (when the mice were 12 weeks old). All BrdU injections were given in the beginning of the active period (the dark period, when the animals were awake), to avoid differences in cytogenesis during the circadian cycles. Four weeks later the animals were euthanized (14 weeks post IR).

Tissue preparation and cutting. Animals were deeply anesthetized with sodium pentobarbital (Pentothal, Electra-box Pharma, Tyresö, Sweden) before being transcardially perfused with a $6 \%$ formaldehyde solution buffered with sodium phosphate at pH 7.4 and stabilized with methanol (Histofix, Histolab products $A B$, Sweden). The brains were immersion-fixed in Histofix for $24 \mathrm{~h}$ after perfusion and then changed to a $30 \%$ sucrose solution containing $100 \mathrm{mM}$ phosphate buffer, $\mathrm{pH} 7.5$. The right hemisphere was cut into $25 \mu \mathrm{m}$ sagittal sections in a series of 12 , using a sliding microtome. The sections were stored in a cryoprotection solution, containing $25 \%$ ethylene glycol and $25 \%$ glycerol, at $4{ }^{\circ} \mathrm{C}$ until staining.

Immunohistochemistry. To block endogenous peroxidases, the sections were treated with $0.6 \%$ hydrogen peroxide for $30 \mathrm{~min}$ and then rinsed in Trisbuffered saline (TBS, $50 \mathrm{mM}$ Tris- $\mathrm{HCl}$ in $150 \mathrm{mM} \mathrm{NaCl}, \mathrm{pH} 7.5) 3 \times 10 \mathrm{~min}$. Sections stained for $\mathrm{BrdU}$ were treated with $2 \mathrm{M} \mathrm{HCl}$ at $37^{\circ} \mathrm{C}$ for $30 \mathrm{~min}$, followed by $10 \mathrm{~min}$ in $100 \mathrm{mM}$ borate buffer ( $\mathrm{pH}$ 8.0). After rinsing with TBS, nonspecific binding was blocked by treating the sections with $3 \%$ donkey serum in TBS with $0.1 \%$ Triton X-100 for 60 min (Jackson Immunoresearch Laboratories Inc, West Grove, PA, USA). Sections were then immediately incubated at $4{ }^{\circ} \mathrm{C}$ with primary antibodies against the microglia marker Iba-1 (rabbit polyclonal anti-lba-1, 1:1000, WAKO Pure Chemical Industries, Itd., Osaka, Japan; 019-19741), BrdU (rat monoclonal anti-BrdU, 1:500, AbD Serotec, Kidlington, UK; OBT0030) or the marker of immature neurons doublecortin (DCX; rabbit polyclonal anti-DCX, 1:1000, Abcam, Cambridge, UK; ab-18723) diluted in $3 \%$ donkey serum in TBS 
containing $0.1 \%$ Triton $X-100$. Anti-lba-1 and anti-BrdU incubations were overnight, anti-DCX incubations were three nights. The sections were rinsed in TBS $(3 \times 10 \mathrm{~min})$ and a biotinylated secondary antibody was added for $1 \mathrm{~h}$ at room temperature (an average of $20^{\circ} \mathrm{C}$; donkey anti-rabbit IgG, 1:1000; donkey anti-rat $\lg G, 1: 1000$ or donkey anti-goat, 1:1000, IgG, all from Jackson Immunoresearch Laboratories Inc, West Grove, PA, USA). The sections were rinsed in TBS $(3 \times 10 \mathrm{~min})$ before a biotin-avidin solution was added for $1 \mathrm{~h}$ (Vectastain ABC Elite kit, Burlingame, CA, USA). The staining was developed using 3-3'-diaminobenzindine tetrahydrochloride (Saveen Werner AB, Malmö, Sweden) diluted in TBS containing hydrogen peroxide and nickel chloride to enhance the reaction. The reaction was stopped using several rinses with tap water and the sections were then placed in TBS before mounting in $0.1 \mathrm{M}$ phosphate buffer ( $\mathrm{pH}$ 7.5). All primary antibodies used in this report are well validated in our laboratory ${ }^{25,57,58}$ and they are included in the Neuroscience Information Framework (http://www.neuinfo.org) list of thoroughly characterized antibodies (numbers 609566, 732011 and 839504 , respectively). Omission of the primary antibodies yielded only very weak nonspecific staining. Furthermore, identification of cells immunopositive for BrdU, DCX and Iba- 1 is facilitated by their characteristic morphology and/or specific localization.

Cell counting and volume assessment. Cells were counted using stereological principles on serially cut sagittal sections (Stereoinvestigator, MicroBrightField, Colchester, VT, USA). The DG areas were traced at $\times 10$ magnification with a DIC filter. All immunopositive cells were counted in every 12th section in the right hemisphere, resulting in four to six sections per animal ( $n=11-14$ animals per group; some brains were lost due to poor perfusion, thereby decreasing the number of animals per group). Iba- 1 and BrdU counts were performed in the entire DG; the GCL subregion, the hilus and the molecular layer of the $D G$ were also counted separately. The $D C X^{+}$cells were counted only in the $S G Z$ of the $G C L$, defined as ranging from three cell layers into the $G C L$ to two cell layers into the hilus as described earlier. ${ }^{22}$ Regional volumes were calculated according to the Cavalieri principle, using the following formula: $V=S A \times P \times T$, in which $V$ is the total volume, SA is the sum of area measurements, $P$ is the inverse of the sampling fraction of the region (in this case $1 / 12$, i.e., $P=12$ ) and $T$ is the section thickness. The total number of cells was obtained by multiplying the number of cells by the sampling fractions.

EPM. The EPM test was performed as described previously with minor modifications. ${ }^{59}$ The plus maze was constructed from black Plexiglass and was set atop an aluminum stand raised $60 \mathrm{~cm}$ above the ground. Two open arms $(25 \times 5 \mathrm{~cm})$ with $0.5 \mathrm{~cm}$ raised edges and two closed arms $(25 \times 5 \mathrm{~cm})$ emerged from a central platform. The closed arm walls measured $25 \mathrm{~cm}$ in height. The test was carried out in a silent, dimly illuminated room in the morning to take the daily variation of hormones and also the mice activity level into consideration. The animals ( $n=13-15$ per group) were placed in the center square of the EPM facing one of the closed arms and behavior was recorded for $5 \mathrm{~min}$. The number of entries into the open arms, and the time spent in open arms were scored.

Open field and place recognition. Open field and place recognition were performed when animals had reached the age of 10 weeks. General locomotor activity was assessed in an open-field arena $\left(50 \times 50 \mathrm{~cm}^{2}\right)$ for 10 min during the first day of the behavior test. The animals were introduced to this unfamiliar arena individually $(n=14)$. The following day, the first day of the place recognition test, two identical objects were placed into the arena. The animals were assessed during $5 \mathrm{~min}$ in each trial. During the second day of the place recognition test one of the object were moved to the opposite corner of the arena. Four arenas were used simultaneously and recorded from above using a CCD camera. The arenas were made of gray plexiglass and the floors were covered with a plastic cover in white to visualize the mice. The arenas were cleaned with $70 \%$ alcohol between each trial. The wall distance and visits to the objects were measured using Viewer ${ }^{3}$ Software (Biobserve GmbH, Bonn, Germany).

Statistical analysis. Data were analyzed using two-way ANOVA, with $P<0.05$ considered statistically significant. For the BrdU and DCX quantifications, where two analyses were performed on the same data sets a Bonferroni correction was used, and $P<0.025$ was considered statistically significant. Statistical analysis was performed using SPSS 19.0 (SPSS, Chicago, IL, USA). All data are shown as mean \pm S.E.M. Significance symbols used for interaction *, irradiation (treatment) \# and sex 0 .

\section{Conflict of Interest}

The authors declare no conflict of interest.

Acknowledgements. This work was supported by the Swedish Childhood Cancer Foundation (Barncancerfonden), the Swedish Research Council (Vetenskapsrådet), the Swedish Cancer Foundation (Cancerfonden), governmental grants from Agreement concerning research and education of doctors (ALF), the Sahlgrenska Academy at the University of Gothenburg, the Sten A. Olsson's Foundation, the Frimurare Barnhus Foundation, the Wilhelm and Martina Lundgren Foundation, the Gothenburg Medical Society, the Aina Wallström's and Mary-Ann Sjöblom's Foundation, the Ulla and Rune Amlöv Foundations, AFA Insurance and the Swedish Society of Medicine. We are grateful for the skillful technical assistance of Rita Grandér.

1. Heyman M, Gustafsson G, Kogner P. Childhood Cancer Incidence and Survival in Sweden 1984-2010 2013 (http://www.cceg.ki.se/documents/ChildhoodCancerlncidenceand SurvivalinSweden1984_2010.pdf).

2. Dreifaldt $A C$, Carlberg $M$, Hardell $L$. Increasing incidence rates of childhood malignant diseases in Sweden during the period 1960-1998. Eur J Cancer 2004; 40: 1351-1360.

3. Rosychuk RJ, Witol A, Wilson B, Stobart K. Central nervous system (CNS) tumor trends in children in a western Canadian province: a population-based 22-year retrospective study. J Neurol 2012; 259: 1131-1136.

4. Smith MA, Seibel NL, Altekruse SF, Ries LA, Melbert DL, O'Leary M et al. Outcomes for children and adolescents with cancer: challenges for the twenty-first century. J Clin Oncol 2010; 28: 2625-2634.

5. Lahteenmaki PM, Harila-Saari A, Pukkala El, Kyyronen P, Salmi TT, Sankila R. Scholastic achievements of children with brain tumors at the end of comprehensive education: a nationwide, register-based study. Neurology 2007; 69: 296-305.

6. Han JW, Kwon SY, Won SC, Shin YJ, Ko JH, Lyu CJ. Comprehensive clinical follow-up of late effects in childhood cancer survivors shows the need for early and well-timed intervention. Ann Oncol 2009; 20: 1170-1177.

7. Fouladi M, Gilger E, Kocak M, Wallace D, Buchanan G, Reeves $C$ et al. Intellectual and functional outcome of children 3 years old or younger who have CNS malignancies. J Clin Oncol 2005; 23: 7152-7160.

8. Mulhern RK, Merchant TE, Gajjar A, Reddick WE, Kun LE. Late neurocognitive sequelae in survivors of brain tumours in childhood. Lancet Oncol 2004; 5: 399-408.

9. Gurney JG, Krull KR, Kadan-Lottick N, Nicholson HS, Nathan PC, Zebrack B et al. Social outcomes in the Childhood Cancer Survivor Study cohort. J Clin Oncol 2009; 27: 2390-2395.

10. Duffner PK. Long-term effects of radiation therapy on cognitive and endocrine function in children with leukemia and brain tumors. Neurologist 2004; 10: 293-310.

11. Habrand JL, De Crevoisier R. Radiation therapy in the management of childhood brain tumors. Childs Nerv Syst 2001; 17: 121-133.

12. Dietrich J, Monje M, Wefel J, Meyers C. Clinical patterns and biological correlates of cognitive dysfunction associated with cancer therapy. Oncologist 2008; 13: 1285-1295.

13. Chin HW, Maruyama Y. Age at treatment and long-term performance results in medulloblastoma. Cancer 1984; 53: 1952-1958.

14. Packer RJ, Meadows AT, Rorke LB, Goldwein JL, D'Angio G. Long-term sequelae of cancer treatment on the central nervous system in childhood. Med Pediatr Oncol 1987; 15: 241-253.

15. Lannering B, Marky I, Lundberg A, Olsson E. Long-term sequelae after pediatric brain tumors: their effect on disability and quality of life. Med Pediatr Oncol 1990; 18: 304-310.

16. Spiegler BJ, Bouffet E, Greenberg ML, Rutka JT, Mabbott DJ. Change in neurocognitive functioning after treatment with cranial radiation in childhood. J Clin Oncol 2004; 22: 706-713.

17. Tada E, Parent JM, Lowenstein DH, Fike JR. X-irradiation causes a prolonged reduction in cell proliferation in the dentate gyrus of adult rats. Neuroscience 2000; 99: 33-41.

18. Fukuda H, Fukuda A, Zhu C, Korhonen L, Swanpalmer J, Hertzman S et al. Irradiationinduced progenitor cell death in the developing brain is resistant to erythropoietin treatment and caspase inhibition. Cell Death Differ 2004; 11: 1166-1178.

19. Raber J, Rola R, LeFevour A, Morhardt D, Curley J, Mizumatsu S et al. Radiation-induced cognitive impairments are associated with changes in indicators of hippocampal neurogenesis. Radiat Res 2004; 162: 39-47.

20. Fukuda A, Fukuda H, Swanpalmer J, Hertzman S, Lannering B, Marky I et al. Age-dependent sensitivity of the developing brain to irradiation is correlated with the number and vulnerability of progenitor cells. J Neurochem 2005; 92: 569-584.

21. Kalm M, Karlsson N, Nilsson MK, Blomgren K. Loss of hippocampal neurogenesis, increased novelty-induced activity, decreased home cage activity, and impaired reversal learning one year after irradiation of the young mouse brain. Exp Neurol 2013; e-pub ahead of print 16 January 2013; doi:10.1016/j.expneurol.2013.01.006.

22. Roughton K, Kalm M, Blomgren K. Sex-dependent differences in behavior and hippocampal neurogenesis after irradiation to the young mouse brain. Eur $\mathrm{J}$ Neurosci 2012; 36: 2763-2772. 
23. Monje ML, Vogel H, Masek M, Ligon KL, Fisher PG, Palmer TD. Impaired human hippocampal neurogenesis after treatment for central nervous system malignancies. Ann Neurol 2007; 62: 515-520.

24. Kalm M, Fukuda A, Fukuda H, Ohrfelt A, Lannering B, Bjork-Eriksson T et al. Transient inflammation in neurogenic regions after irradiation of the developing brain. Radiat Res 2009; 171: 66-76

25. Kalm M, Lannering B, Bjork-Eriksson T, Blomgren K. Irradiation-induced loss of microglia in the young brain. $J$ Neuroimmunol 2009; 206: 70-75.

26. Monje ML, Mizumatsu S, Fike JR, Palmer TD. Irradiation induces neural precursor-cell dysfunction. Nat Med 2002; 8: 955-962.

27. Monje ML, Toda H, Palmer TD. Inflammatory blockade restores adult hippocampal neurogenesis. Science 2003; 302: 1760-1765.

28. Garden GA, Moller T. Microglia biology in health and disease. J Neuroimmune Pharmacol 2006; 1: 127-137.

29. Russo I, Barlati S, Bosetti F. Effects of neuroinflammation on the regenerative capacity of brain stem cells. J Neurochem 2011; 116: 947-956.

30. Shaw KN, Commins S, O'Mara SM. Lipopolysaccharide causes deficits in spatial learning in the watermaze but not in BDNF expression in the rat dentate gyrus. Behav Brain Res 2001; 124: 47-54

31. Wu CW, Chen YC, Yu L, Chen HI, Jen CJ, Huang AM et al. Treadmill exercise counteracts the suppressive effects of peripheral lipopolysaccharide on hippocampal neurogenesis and learning and memory. J Neurochem 2007; 103: 2471-2481.

32. Roughton K, Andreassen U, Blomgren K, Kalm K. Lipopolysaccharide-induced inflammation aggravates irradiation-induced injury to the young mouse brain. Dev Neurosci 2013; 35: 406-415.

33. Ris MD, Packer R, Goldwein J, Jones-Wallace D, Boyett JM. Intellectual outcome after reduced-dose radiation therapy plus adjuvant chemotherapy for medulloblastoma: a Children's Cancer Group study. J Clin Oncol 2001; 19: 3470-3476.

34. Hagberg H, Dammann O, Mallard C, Leviton A. Preconditioning and the developing brain Semin Perinatol 2004; 28: 389-395.

35. Vallieres L, Rivest S. Regulation of the genes encoding interleukin-6, its receptor, and gp130 in the rat brain in response to the immune activator lipopolysaccharide and the proinflammatory cytokine interleukin-1beta. J Neurochem 1997; 69: 1668-1683.

36. Turrin NP, Gayle D, llyin SE, Flynn MC, Langhans W, Schwartz GJ et al. Pro-inflammatory and anti-inflammatory cytokine mRNA induction in the periphery and brain following intraperitoneal administration of bacterial lipopolysaccharide. Brain Res Bull 2001; 54: 443-453.

37. Mallard C, Hagberg $\mathrm{H}$. Inflammation-induced preconditioning in the immature brain. Semin Fetal Neonatal Med 2007; 12: 280-286.

38. Bostrom M, Kalm M, Karlsson N, Hellstrom Erkenstam N, Blomgren K. Irradiation to the young mouse brain caused long-term, progressive depletion of neurogenesis but did not disrupt the neurovascular niche. J Cereb Blood Flow Metab 2013; 33: 935-943.

39. Hellstrom NA, Bjork-Eriksson T, Blomgren K, Kuhn HG. Differential recovery of neural stem cells in the subventricular zone and dentate gyrus after ionizing radiation. Stem Cells 2009; 27: 634-641.

40. Ekdahl CT, Claasen JH, Bonde S, Kokaia Z, Lindvall O. Inflammation is detrimental for neurogenesis in adult brain. Proc Natl Acad Sci USA 2003; 100: 13632-13637.

41. Ekdahl CT. Microglial activation - tuning and pruning adult neurogenesis. Front Pharmacol 2012; 3: 41.

42. Kohman RA, Rhodes JS. Neurogenesis, inflammation and behavior. Brain Behav Immun 2013; 27: 22-32.

43. Clark PJ, Brzezinska WJ, Thomas MW, Ryzhenko NA, Toshkov SA, Rhodes JS. Intact neurogenesis is required for benefits of exercise on spatial memory but not moto performance or contextual fear conditioning in C57BL/6 J mice. Neuroscience 2008; 155 : 1048-1058.

44. Redmond KJ, Mahone EM, Terezakis S, Ishaq O, Ford E, McNutt T et al. Association between radiation dose to neuronal progenitor cell niches and temporal lobes and performance on neuropsychological testing in children: a prospective study. Neuro-oncology 2013; 15: 360-369.

45. Zhao C, Deng W, Gage FH. Mechanisms and functional implications of adult neurogenesis. Cell 2008; 132: 645-660.

46. Laplagne DA, Kamienkowski JE, Esposito MS, Piatti VC, Zhao C, Gage FH et al. Similar GABAergic inputs in dentate granule cells born during embryonic and adult neurogenesis. Eur J Neurosci 2007; 25: 2973-2981.

47. Whitton PS. Inflammation as a causative factor in the aetiology of Parkinson's disease. Br J Pharmacol 2007; 150: 963-976.

48. Eichenbaum H. A cortical-hippocampal system for declarative memory. Nat Rev Neurosci 2000; 1: 41-50.

49. Karlsson N, Kalm M, Nilsson MK, Mallard C, Bjork-Eriksson T, Blomgren K. Learning and activity after irradiation of the young mouse brain analyzed in adulthood using unbiased monitoring in a home cage environment. Radiat Res 2011; 175: 336-346.

50. Villasana L, Rosenberg J, Raber J. Sex-dependent effects of $56 \mathrm{Fe}$ irradiation on contextual fear conditioning in C57BL/6 J mice. Hippocampus 2010; 20: 19-23.

51. Yeiser LA, Villasana LE, Raber J. ApoE isoform modulates effects of cranial (5)(6)Fe irradiation on spatial learning and memory in the water maze. Behav Brain Res 2013; 237: 207-214.

52. Lin YL, Lin SY, Wang S. Prenatal lipopolysaccharide exposure increases anxiety-like behaviors and enhances stress-induced corticosterone responses in adult rats. Brain Behav Immun 2012; 26: 459-468.

53. Fanselow MS, Dong HW. Are the dorsal and ventral hippocampus functionally distinct structures? Neuron 2010; 65: 7-19.

54. Fowler JF. The linear-quadratic formula and progress in fractionated radiotherapy. Br J Radiol 1989; 62: 679-694.

55. Whitaker JR, Granum PE. An absolute method for protein determination based on difference in absorbance at 235 and 280nm. Anal Biochem 1980; 109: $156-159$

56. Wang X, Karlsson JO, Zhu C, Bahr BA, Hagberg H, Blomgren K. Caspase-3 activation after neonatal rat cerebral hypoxia-ischemia. Biol Neonate 2001; 79: 172-179.

57. Lindwall C, Olsson M, Osman AM, Kuhn HG, Curtis MA. Selective expression of hyaluronan and receptor for hyaluronan mediated motility (Rhamm) in the adult mouse subventricular zone and rostral migratory stream and in ischemic cortex. Brain Res 2013; 1503: $62-77$.

58. Zhu C, Gao J, Karlsson N, Li Q, Zhang Y, Huang Z et al. Isoflurane anesthesia induced persistent, progressive memory impairment, caused a loss of neural stem cells, and reduced neurogenesis in young, but not adult, rodents. J Cereb Blood Flow Metab 2010; 30: 1017-1030.

59. Komada M, Takao K, Miyakawa T. Elevated plus maze for mice. J Vis Exp 2008; 1088.

(c) (7) $\odot$ Cell Death and Disease is an open-access journal Cy ${ }_{\text {NC ND }}$ published by Nature Publishing Group. This work is licensed under a Creative Commons Attribution-NonCommercialNoDerivs 3.0 Unported License. To view a copy of this license, visit http://creativecommons.org/licenses/by-nc-nd/3.0/ 